\title{
Multiple risk factors affecting childhood psychosocial dysfunction in primary school Egyptian children
}

\author{
Eman S. Soliman ${ }^{1,2^{*}}$, Rehab S. Mahdy ${ }^{2}$, Heba A. Fouad ${ }^{2}$, R. A. Abbas ${ }^{3}$ and Amel Fayed ${ }^{1}$ (D)
}

\begin{abstract}
Background: Childhood psychosocial dysfunction (CPD) is an important cause of morbidity among children, and its frequency in primary care is growing. The information about its prevalence and risk factors is weak in many developing countries. The study aims to determine the prevalence of psychosocial problems among primary school children and identify the risk factors associated with childhood psychosocial dysfunction.
\end{abstract}

Results: A cross-sectional study was conducted on 368 primary school children aged 6-12 years. About (19.0\%) of the studied sample had probable CPD according to Strengths and Difficulties Questionnaire (SDQ). CPD was statistically associated with older age group, male sex, and low social class.

The association between biological and medical risk factors of the studied group and CPD showed statistical significant relations between CPD and low body weight $(n=35,50.7 \%)$, maternal history of problems with pregnancy $(n=26,66.47 \%)$, history of receiving medications during pregnancy $(n=13,86.7 \%)$, abnormal general condition of baby at birth $(n=57$, 16.2\%), family history of mental disorders $(n=2,100 \%)$, medical history of congenital diseases $(n=9,90 \%)$, acute medical disorders $(n=29,90.6 \%)$, chronic diseases, receiving medications $(n=22,91.7 \%)$, and exposure to trauma $(n=27,84.4 \%)$. Also, The association between psychosocial risk factors and CPD revealed high statistical significant relation between CPD among the studied children and presence of family problems $(n=33,62.3 \%)$, living with single parent $(n=15,71.4 \%)$, parent(s) death $(n=12,63.2 \%)$, major changes in the family $(n=39,79.6 \%)$, parent(s) smoking status $(n=22,51.2 \%)$, and parent(s) addiction $(n=4,100 \%)$.

Moreover, there was statistical significant relation between CPD among the studied children and poor academic achievement $(n=19,27.5 \%)$, problems with teachers $(n=25,33.3 \%)$, problems with peers $(n=22,51.2 \%)$, and exposure to violence $(n=56,22.4 \%)$.

Conclusions: Psychosocial dysfunction is common among Egyptian school children. It is associated with many risk factors. Hence, mental health services should be incorporated into primary health care facilities and school health program. Also, training of family physicians and primary health care providers is crucial.

Keywords: Psychosocial, Primary school, Strengths and difficulties questionnaire (SDQ), Child psychiatry

\section{Background}

The term psychosocial is used to emphasize the close connection between psychological aspects of the human

\footnotetext{
* Correspondence: dr_eman_alex@yahoo.com

${ }^{1}$ Clinical Science Department, College of Medicine, Princess Nourah Bint Abdulrahman University, Riyadh, Kingdom of Saudi Arabia

${ }^{2}$ Psychiatry Department, Faculty of Medicine, Zagazig University, Zagazig, Egypt Full list of author information is available at the end of the article
}

experience and the wider social experience. Psychological effects are those that affect different levels of functioning including cognitive (perception and memory as a basis for thoughts and learning), affective (emotions), and behavioral. Social effects concern relationships, family and community networks, cultural traditions, and economic status, including life tasks such as school or work. Emotional, behavioral, and psychiatric problems in children are a

\section{Springer Open}

() The Author(s). 2020 Open Access This article is licensed under a Creative Commons Attribution 4.0 International License, which permits use, sharing, adaptation, distribution and reproduction in any medium or format, as long as you give appropriate credit to the original author(s) and the source, provide a link to the Creative Commons licence, and indicate if changes were made. The images or other third party material in this article are included in the article's Creative Commons licence, unless indicated otherwise in a credit line to the material. If material is not included in the article's Creative Commons licence and your intended use is not permitted by statutory regulation or exceeds the permitted use, you will need to obtain permission directly from the copyright holder. To view a copy of this licence, visit http://creativecommons.org/licenses/by/4.0/. 
substantial public health problem in developing countries despite being less extensively studied and monitored than causes of physical mortality and morbidity such as infection, nutrition, and injury [1].

Childhood psychosocial dysfunction (CPD), such as aggressive behavior, fear, and anxiety, is common in children and may lead to restrictions in daily functioning. According to population-based studies, $20 \%$ of children have some degree of psychosocial problems [2].

$\mathrm{CPD}$ in children represents a considerable expense to society and is an important reason for using health care. Moreover, these problems can have a large effect on a child's future life that the earlier child behavioral problems commence, the greater the risk that they will become worse and persist in adulthood [3].

Epidemiological information about prevalence of child mental health problems is essential to inform policy and public health practice. This information is weak in many developing countries and those in developmental transition. There have been few such studies in Arab countries and none in Egypt [4].

CPD is among the most prevalent chronic health conditions of childhood and often has serious negative consequences for a child's academic achievement and social development [5]. This range of disorders may be caused by a number of factors such as parenting style which is inconsistent or contradictory, family or marital problems, child abuse or neglect, injury or chronic illness, and separation [6].

Childhood is a developmental stage in which the importance of reciprocal emotional bonding between a child and his/her caregivers, for healthy physical, psychological, and social development, has been known for centuries [7].

Several studies reported different estimates for the prevalence of CPD among children that ranged from 19.0 to $34.7 \%$ [4, 8-10]. Prevalence rates vary with age, methods used, and sample [10]. It is crucial to notice the substantial discrepancy between the prevalence rates and the number of $\mathrm{CPD}$ being treated. One of the causes may be the stigma associated with mental health care [11] or limited access to care [12]. Another explanation might be that CPD in the community is often not recognized or diagnosed [13].

The CPD is often multi-factorial and the way in which they are expressed may be influenced by a range of factors including developmental stage, temperament, coping and adaptive abilities of family, and the nature and the duration of stress. In general, chronic stressors are more difficult to deal with than isolated stressful events [14].

Community pediatric services, like those in the USA and the Netherlands, offering routine health care services to the population as a whole, are in a unique position to detect children with psychosocial problems. In the Netherlands, this early detection is an explicitly formulated task of the existing Preventive Child Healthcare (PCH). This health examination includes both physical and mental health. When problems are detected, children are referred to the family doctor or specialized care [9]. Primary Health Care (PHC) reaches about 95\% of all children. Without reliable and valid questionnaires, many children with mental health problems are likely to be missed [10].

Only a minority of children with such problems is treated for these problems. It was found that only 13\% of children with behavioral or emotional problems were referred to mental health care [15]. Reliable and valid questionnaires can improve early detection of such problems and the following treatment will improve their prognosis significantly and substantively [16]. The present study aimed at (1) determining the prevalence of CPD among a sample of primary school children in Egypt and (2) identifying risk factors associated with childhood psychosocial dysfunction (CPD).

\section{Methods}

\section{Study design and setting}

Proposal acceptance was obtained from the Institutional Review Board (IRB) of Faculty of Medicine, Zagazig University. Formal permission was taken from an educational administration in ministry of education. Parents and teachers were asked to sign an informed consent after explaining the purpose of the study and assuring them regarding data confidentiality.

A pilot study was conducted on 20 parents and 5 teachers of the studied primary school children from the two randomly selected primary schools in order to test the questionnaire, the logistic problems of the field work, and to form a general idea about the prevalence and risk factors of CPD among the studied sample. Parents and teachers who were included in the pilot study were not included in the main survey.

A cross-sectional study was conducted on 368 primary school children aged 6-12 years in two randomly selected primary public schools in Nile delta region, Sharqiyah Governorate, Egypt. One in a rural area (Abo Nemer School) and the other in an urban area (El Loghat School) throughout the period from September 1, 2013 to the end of December 2013. A simple random sample was taken from the registered children attending both schools aged 6-12 years old. Children whose parents could not be interviewed and children with special needs were excluded. For each recruited child, a parent(s) and teacher were asked to complete a structured questionnaire with socio-demographic data, biological and medical risk factors, CPD risk factors, and Strengths and Difficulties Questionnaire (SDQ).

Also, body mass index (BMI) was estimated for each studied child.

Socio-demographic characteristics: child characteristic (age, sex, number of children in the family and birth order, residence, educational background of parents, 
parents' occupation, family size, family income, and socioeconomic status). Scoring of socioeconomic status (SES) for health research in EGYPT, this scale includes 7 domains with a total score of 84 [17].

1. Education and cultural domain (score 30)

2. Occupation domain (score 10)

3. Family domain (score 10)

4. Family possessions domain (score 12)

5. Home sanitation domain (score 12)

6. Economic domain (score 5)

7. Health care domain (score 5)

Grading of (SES):

Very low $(0-21)$

Low (22-42)

Middle (43-63)

High (above 63 score)

\section{Tools}

i. Biological and medical risk factors questionnaire: it contains questions for mothers about any problems in pregnancy, history of taking medications during pregnancy, and general condition of baby at birth. Also, questions for child in form of any family history of mental disorders, medical history of congenital diseases, history of acute or chronic diseases, taking recent medication and past history of accident, and burn and trauma.

ii. Childhood psychosocial dysfunction risk factors questionnaire: it contains questions in form of any family problems, is the child living with his/her parents or a single parent, parent's death, major changes in the family, smoking and drug abuser of any parents, child academic achievement, problems with teachers and peers, exposure to violence, living near pollution, and using computer and television for a long time.

iii. The Arabic version of the extended strengths and difficulties questionnaire SDQ [18]:

This is a brief behavioral questionnaire that includes 25 core items. The 25 items generate five scales: emotional symptoms, conduct problems, hyperactivity/inattention, peer relationship problems, and pro-social behavior. Each of these scales is scored from 0 to 10 and can be classed as "normal," "borderline," or "abnormal" depending on how the score compares with population standards based on original validation work in the UK. All but the last scale is summed to generate a total difficulties score ranging from 0 to 40 [19]. A standardized computer algorithm to predict child psychiatric disorders has been developed, which uses information on symptoms and impact from all the available informants (in this case, both parents and teachers) for any individual child. This distinguishes between three groups of disorders, namely conductoppositional disorders, hyperactivity-inattention disorders, and anxiety-depressive disorders. Each is predicted to be "unlikely", "possible," or "probable." Predictions of the three groups are combined to generate an overall prediction of the presence or absence of any psychiatric disorders [20]. There was a very good agreement between parents and teachers regarding grading of SDQ into three categories (diagnosed, borderline, and undiagnosed) Kappa $=0.95,95 \%$, confidence interval (CI) (0.88-1.00). There was one case of disagreement which was interviewed by a researcher and found to belong to diagnosed category.

\section{iv. BMI estimation}

Weight in $\mathrm{kg}$ and height in meter for each child were measured and calculated by WHO formula; a person's weight in kilograms divided by the square of the person's height in meters $(\mathrm{kg} / \mathrm{m} 2)$ [21]. After BMI is calculated for children and teens, it is expressed as a percentile. The WHO growth reference for age 5-19 was used to categorize groups into underweight, normal, overweight, and obese [22] (Table 1).

\section{Data analysis}

The collected data was analyzed by the SPSS version PASW Statistics for Windows, Version 20.0. Chicago: SPSS Inc. Comparison between categorical variables was done using chi squared and Fisher exact tests. The result was considered statistically significant if $P$ value $<0.05$.

\section{Results}

Table 2 is showing socio-demographic characteristics of the studied Group. The age of the studied children ranged from 6 to 12 years with a mean of $(8.48 \pm 1.76)$. The majority of them aged between $(6-<9)$ years (53.0\%). Females represented slightly more than half of the studied group (60.3\%). Nearly half of the studied samples were from an urban area (57.1\%) and had middle rank (47.3\%). The majority of studied sample was of middle socioeconomic level (55.4\%), while those from high socioeconomic level represented only (15.5\%).

Table 1 Weight status category and percentile range

\begin{tabular}{ll}
\hline Weight status category & Percentile range \\
\hline Underweight & Less than the 5th percentile \\
$\begin{array}{l}\text { Normal or healthy } \\
\text { weight }\end{array}$ & $\begin{array}{l}\text { pth percentile to less than the 85th } \\
\text { percentile }\end{array}$ \\
Overweight & 85th to less than the 95th percentile \\
Obese & Equal to or greater than the 95th percentile \\
\hline
\end{tabular}


Table 2 Socio-demographic characteristics of the studied group

\begin{tabular}{|c|c|c|c|}
\hline \multirow{2}{*}{\multicolumn{2}{|c|}{ Socio-demographic characteristics }} & \multirow{2}{*}{\multicolumn{2}{|c|}{ The studied group $(N=368)$}} \\
\hline & & & \\
\hline \multirow[t]{2}{*}{ Age (years) } & & \multicolumn{2}{|c|}{$8.48 \pm 1.76(6-12)$} \\
\hline & & N & $\%$ \\
\hline \multirow[t]{2}{*}{ Age } & $6-<9$ & 195 & 53.0 \\
\hline & $9-12$ & 173 & 47.0 \\
\hline \multirow[t]{2}{*}{ No. of brother and sisters } & $\leq 2$ & 234 & 63.6 \\
\hline & $>2$ & 134 & 36.4 \\
\hline \multirow[t]{2}{*}{ Sex } & Male & 146 & 39.7 \\
\hline & Female & 222 & 60.3 \\
\hline \multirow[t]{2}{*}{ Residence } & Urban & 210 & 57.1 \\
\hline & Rural & 158 & 42.9 \\
\hline \multirow[t]{3}{*}{ Child order } & First & 117 & 31.8 \\
\hline & Middle & 174 & 47.3 \\
\hline & Last & 77 & 20.9 \\
\hline \multirow[t]{4}{*}{ Socioeconomic status level } & Very low & 6 & 1.6 \\
\hline & Low & 101 & 27.4 \\
\hline & Middle & 204 & 55.4 \\
\hline & High & 57 & 15.5 \\
\hline
\end{tabular}

Table 3 displays the distribution of the studied children according to SDQ as reported by parents and teachers.

Table 4 represents the association between sociodemographic characteristics of the studied children and CPD. CPD was statistically associated with older age group $(P=$ $0.03)$, male sex $(P=0.012)$, and low social class $(P=0.001)$. On the other hand, there was no statistical significant relation between psychosocial dysfunction and number of sisters and brothers, residence, and child order $(P>0.05)$.

Table 5 reveals the association between biological and medical risk factors of the studied group and CPD. There were statistical significant relations between CPD of the studied children and low body weight $(n=35$, $50.7 \%)(P=0.001)$, maternal history of problems with pregnancy $(n=26,66.47 \%)(P=0.001)$, history of receiving medications during pregnancy $(n=13,86.7 \%)(P=$ $0.001)$, abnormal general condition of baby at birth $(n=$ $57,16.2 \%)(P=0.001)$, and family history of mental disorders $(n=2,100 \%)(P<0.04)$. There were also statistical

Table 3 Parents and teachers assessment of CPD among the studied children according to Strengths and Difficulties Questionnaire (SDQ)

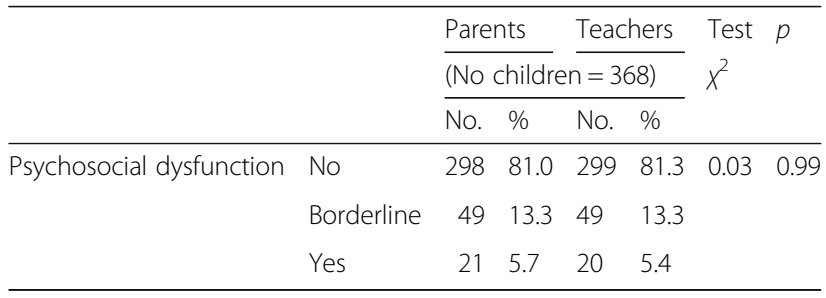

significant relations between psychosocial dysfunction and medical history of congenital diseases $(n=9,90 \%)$ $(P=0.001)$, acute medical disorders $(n=29,90.6 \%)(P=$ $0.001)$, chronic diseases, and receiving medications $(n=$ $22,91.7 \%)(P=0.001)$. There was high statistically significant relation between psychosocial dysfunction among the studied sample and exposure to trauma ( $n=27,84.4 \%)$ $(P=0.001)$. On the other hand, there was low degree of statistically significant relation between CPD among the studied group and history of accidents and burn $(P>0.05)$.

Table 6 shows the association between psychosocial risk factors and CPD. There was high statistical significant relation between CPD among the studied children and presence of family problems $(n=33,62.3 \%)(P=0.001)$, living with single parent $(n=15,71.4 \%)(P=0.001)$, parent(s) death $(n=12,63.2 \%)(P=0.001)$, major changes in the family $(n=39,79.6 \%)$, parent(s) smoking status $(n=22$, $51.2 \%)$, and parent(s) addiction $(n=4,100 \%)(P=0.001)$. There was statistical significant relation between psychosocial dysfunction among the studied children and poor academic achievement $(n=19,27.5 \%)(P=0.04)$, problems with teachers $(n=25,33.3 \%)(P=0.001)$, problems with peers $(n=22,51.2 \%)(P=0.001)$, and exposure to violence ( $n=56,22.4 \%)(P=0.02)$. On the other hand, there was no statistical significant relation between psychosocial dysfunction among the studied children and living nearby a source of pollution $(P=0.29)$.

\section{Discussion}

In the present study, the age of the studied children ranged from 6 to 12 years. The selection of this age group is important because this period of life is crucial for healthy physical, emotional, and social development and acquisition of effective coping skills [23].

The results of the present study showed that $19.0 \%$ and $18.7 \%$ of the studied sample of children as reported by parents and teachers, respectively, had probable CPD, according to SDQ. Similar findings were revealed in US children surveillance, where a total of $13-20 \%$ of the studied children experienced a mental disorder [24]. Moreover, other studies had shown that between 13\% and $18 \%$ of preschool children suffer from some sort of psychopathology [25].

However, in an Egyptian study of emotional and behavioral disorders among children aged 6 to 12 years old in Minia using SDQ, the prevalence was higher than that of our present study $(34.7 \%$ and $20.6 \%$ as reported by teachers and parents, respectively) [4]. A high prevalence of CPD (34.5\%) was found also in Pakistan and Bangladesh [26, 27]. It is possible that this pattern of high prevalence of problem symptoms is a specific feature of developing countries during the period of transition [4]. 
Table 4 Association between socio-demographic characteristics of the studied children and CPD

\begin{tabular}{|c|c|c|c|c|c|c|c|}
\hline \multirow[t]{3}{*}{ Socio-demographic characteristics } & & \multicolumn{4}{|c|}{ Psychosocial dysfunction } & \multirow{3}{*}{$\begin{array}{l}\text { Test } \\
x^{2 a}\end{array}$} & \multirow[t]{3}{*}{$p$} \\
\hline & & \multicolumn{2}{|c|}{ Yes $(N=70)$} & \multicolumn{2}{|c|}{ No $(N=298)$} & & \\
\hline & & No. & $\%$ & No. & $\%$ & & \\
\hline \multirow[t]{2}{*}{ Age } & $6-<9$ & 29 & 14.9 & 166 & 85.1 & \multirow[t]{2}{*}{4.64} & \multirow[t]{2}{*}{$0.03^{a}$} \\
\hline & $9-12$ & 41 & 23.7 & 132 & 76.3 & & \\
\hline \multirow[t]{2}{*}{ Number of sisters and brothers } & $\leq 2$ & 46 & 19.7 & 188 & 80.3 & \multirow[t]{2}{*}{0.17} & \multirow[t]{2}{*}{0.68} \\
\hline & $>2$ & 24 & 17.9 & 110 & 82.1 & & \\
\hline \multirow[t]{2}{*}{ Sex } & Male & 37 & 25.3 & 109 & 74.7 & \multirow[t]{2}{*}{6.28} & \multirow[t]{2}{*}{$0.012^{a}$} \\
\hline & Female & 33 & 14.9 & 189 & 85.1 & & \\
\hline \multirow[t]{2}{*}{ Residence } & Urban & 37 & 17.6 & 173 & 82.4 & \multirow[t]{2}{*}{0.62} & \multirow[t]{2}{*}{0.43} \\
\hline & Rural & 33 & 20.9 & 125 & 79.1 & & \\
\hline \multirow[t]{3}{*}{ Child order } & First & 23 & 19.7 & 94 & 80.3 & \multirow[t]{3}{*}{3.83} & \multirow[t]{3}{*}{0.15} \\
\hline & Middle & 27 & 15.5 & 147 & 84.5 & & \\
\hline & Last & 20 & 26.0 & 57 & 74.0 & & \\
\hline \multirow[t]{4}{*}{ Social class } & Very low & 5 & 8.3 & 1 & 81.7 & \multirow[t]{4}{*}{23.8} & \multirow[t]{4}{*}{0.001} \\
\hline & Low & 27 & 26.7 & 74 & 73.3 & & \\
\hline & Middle & 28 & 13.7 & 176 & 86.3 & & \\
\hline & High & 10 & 17.5 & 47 & 82.5 & & \\
\hline
\end{tabular}

${ }^{a} x^{2}$ or exact test as appropriate

Our results revealed there was no statistically significant difference between parents and teachers regarding the diagnostic result of SDQ. Alternatively, other studies revealed higher frequency of CPD using SDQ reported by teachers than that reported by parents $(11.1 \%$ vs $8.7 \%$ in UK and $34.7 \%$ vs $20.6 \%$ in Egypt) $[4,28]$. This result may be due to the fact that high rates of externalizing problem behaviors are usually reported by teachers among their students and this might account for the greater problem rates [4]. On the other hand, some parental expectations are of stricter self-control among younger children, leading to higher rates of perceived (but perhaps nonpathological) problems [4]. So, many researchers stressed on the importance of collecting information from the two informants (parents and teachers) [26].

In the present study, CPD was statistically associated with older age group (children aged 9-12 years old). This result agrees with that of other studies, where mental disorders in childhood were found to increase with age [24].

Research results show that a higher percentage of males (25.3\%) was diagnosed by SDQ to have CPD compared to a lower percentage of females (14.9\%). This result agrees with that of another Egyptian study that was conducted in Minia where 22.0\% of the studied males were diagnosed to have CPD compared to a lower percentage of females (19.2\%) [4].

Moreover, our result agrees with that of another study, where a person's socioeconomic class was found to outline the psychosocial, environmental, behavioral, and biomedical risk factors that are associated with mental health
[29]. Also, in another study, mental illness and poverty were considered to interact in a negative cycle [30].

Also, there were statistical significant relations between CPD of the studied children and their body mass index (BMI), maternal history of problems with pregnancy, history of receiving medications during pregnancy, abnormal general condition of baby at birth, and family history of mental disorders $(P<0.05)$. A significantly higher percentage of children's mothers with CPD (66.7\%) had experienced problems during pregnancy compared to (13.4\%) with no history of problems during pregnancy. Similarly, another study suggested increased rates of schizophrenia in offspring for women suffered from problems during pregnancy [22].

Moreover, many of the putative prenatal risks such as maternal smoking, stress, and diseases in pregnancy are ones that tend to be associated with postnatal risks including offspring psychiatric disorders. However, as mothers transmit genes to their offspring, there is a possibility that the associations arise through mothers and offspring sharing some of their genome rather than because of a true prenatal risk effect [31]. Swanson \& Wadhwa [32] reported that exposure to early adversity during a sensitive period of development is thought to lead to structural, physiological, and metabolic changes in the fetus that do not cause recognizable defects but increase susceptibility to later disease. Also, malnutrition, low birth weight, and certain micronutrient deficiencies (such as iodine deficiency) significantly increased the risk to brain development, as do risky 
Table 5 Association between biological and medical risk factors of the studied group and CPD

\begin{tabular}{|c|c|c|c|c|c|c|}
\hline \multirow[t]{3}{*}{ Biological and medical risk factors } & & \multicolumn{4}{|c|}{ Psychosocial dysfunction } & \multirow[t]{3}{*}{$p$} \\
\hline & & \multicolumn{2}{|c|}{ Yes $(N=70)$} & \multicolumn{2}{|c|}{ No $(N=298)$} & \\
\hline & & No & $\%$ & No & $\%$ & \\
\hline \multirow[t]{4}{*}{ BMI of the child } & Underweight & 35 & 50.7 & 34 & 49.3 & $0.001^{a}$ \\
\hline & Normal & 19 & 8.6 & 201 & 91.4 & \\
\hline & Overweight & 9 & 17.0 & 44 & 83.0 & \\
\hline & Obese & 7 & 27.0 & 19 & 73.0 & \\
\hline \multirow[t]{2}{*}{ Problems during pregnancy } & Yes & 26 & 66.47 & 13 & 33.3 & $0.001^{a}$ \\
\hline & No & 44 & 13.4 & 285 & 86.6 & \\
\hline \multirow[t]{2}{*}{ History of acute medical disorders } & Yes & 29 & 90.6 & 3 & 9.4 & $0.001^{a}$ \\
\hline & No & 41 & 12.2 & 295 & 78.8 & \\
\hline \multirow[t]{2}{*}{ Taking medications } & Yes & 26 & 92.9 & 2 & 7.1 & $0.001^{a}$ \\
\hline & No & 44 & 13.0 & 296 & 87.0 & \\
\hline \multirow[t]{2}{*}{ Exposure to trauma } & Yes & 27 & 84.4 & 5 & 15.6 & $0.001^{a}$ \\
\hline & No & 43 & 12.8 & 293 & 87.2 & \\
\hline \multirow[t]{2}{*}{ Taking medications during pregnancy } & Yes & 13 & 86.7 & 2 & 13.3 & $0.001^{a}$ \\
\hline & No & 57 & 16.0 & 296 & 84.0 & \\
\hline \multirow[t]{2}{*}{ General condition of baby at birth } & Normal & 57 & 16.2 & 294 & 83.8 & $0.001^{a}$ \\
\hline & Abnormal & 13 & 76.5 & 4 & 23.5 & \\
\hline \multirow[t]{2}{*}{ Family history of mental disorders } & Yes & 2 & 100.0 & 0 & 0.0 & 0.04 \\
\hline & No & 68 & 18.6 & 298 & 81.4 & \\
\hline \multirow[t]{2}{*}{ History of congenital diseases } & Yes & 9 & 90.0 & 1 & 10.0 & $0.001^{a}$ \\
\hline & No & 61 & 17.0 & 29 & 83.0 & \\
\hline \multirow[t]{2}{*}{ History of chronic diseases } & Yes & 22 & 91.7 & 2 & 8.3 & $0.001^{a}$ \\
\hline & No & 48 & 14.0 & 296 & 86.2 & \\
\hline \multirow[t]{2}{*}{ Exposure to accidents } & Yes & 7 & 32 & 15 & 68 & 0.10 \\
\hline & No & 63 & 18.2 & 283 & 81.8 & \\
\hline \multirow[t]{2}{*}{ Exposure to burn } & Yes & 2 & 66.7 & 1 & 33.3 & $0.09^{a}$ \\
\hline & No & 68 & 18.6 & 297 & 81.4 & \\
\hline
\end{tabular}

${ }^{a} x^{2}$ or exact test as appropriate

health behaviors in pregnancy, especially the use of tobacco and drugs [33, 34].

Moreover, another study found a significant relation between BMI and CPD among young children which become a risk factor to eating disorder [14]. An increased risk of psychosocial distress such as negative selfperception, social, or behavior problems was found among a subset of obese children and adolescents [35].

In the present study, there were significant relations between CPD of the studied children and history of congenital diseases, acute medical disorders, chronic diseases, and receiving medications. Similarly, several surveys have found that chronically ill children are at greater risk for developing behavioral or emotional problems than healthy children, although such effects have not been found for all categories of chronic diseases [36]. The increasing understanding of brain plasticity (neuroplasticity) raises questions of whether infections or toxins trigger a change in the brain chemistry, which can develop into a mental disorder [37].

In the current study, there was high statistically significant relation between CPD among the studied sample of children and past history of trauma (psychic or physical). Similarly, several studies proved that exposure to trauma (psychic or physical) that is associated with marked effect on body or feelings was associated with increased risk of CPD in the children [36].

Added results, there was high statistically significant relation between CPD among the studied children and family problems, living with single parent, parent(s) death, major changes in the family, and parent(s) addiction. Loss of one or both parents can have negative effect on the psychosocial status of children. The individual may feel fear, guilt, anger, or loneliness. This can drive a person into solitude and depression [36]. 
Table 6 Association between psychosocial risk factors and CPD

\begin{tabular}{|c|c|c|c|c|c|c|}
\hline \multirow[t]{3}{*}{ Psychosocial risk factors } & & \multicolumn{4}{|c|}{ Psychosocial dysfunction } & \multirow[t]{3}{*}{$p$} \\
\hline & & \multicolumn{2}{|c|}{ Yes $(N=70)$} & \multicolumn{2}{|c|}{ No $(N=298)$} & \\
\hline & & No & $\%$ & No. & $\%$ & \\
\hline \multirow[t]{2}{*}{ Family problems } & Yes & 33 & 62.3 & 20 & 37.7 & $0.001^{a}$ \\
\hline & No & 37 & 11.7 & 278 & 88.3 & \\
\hline \multirow[t]{2}{*}{ Major changes in the family } & Yes & 39 & 79.6 & 10 & 20.4 & $0.001^{a}$ \\
\hline & No & 31 & 9.7 & 288 & 90.3 & \\
\hline \multirow[t]{2}{*}{ Parent(s) smoking status } & Yes & 22 & 51.2 & 21 & 48.8 & $0.001^{\mathrm{a}}$ \\
\hline & No & 48 & 14.8 & 277 & 85.2 & \\
\hline \multirow[t]{2}{*}{ Academic achievement at school } & Satisfactory & 51 & 17.1 & 248 & 82.9 & 0.04 \\
\hline & Poor to very poor & 19 & 27.5 & 50 & 72.5 & \\
\hline \multirow[t]{2}{*}{ Problems with teachers } & Yes & 25 & 33.3 & 50 & 66.7 & $0.001^{\mathrm{a}}$ \\
\hline & No & 45 & 15.4 & 248 & 84.6 & \\
\hline \multirow[t]{2}{*}{ Problems with peers } & Yes & 22 & 51.2 & 21 & 48.8 & $0.001^{\mathrm{a}}$ \\
\hline & No & 48 & 14.8 & 277 & 85.2 & \\
\hline \multirow[t]{2}{*}{ Exposure to violence } & Yes & 56 & 22.4 & 194 & 77.6 & 0.02 \\
\hline & No & 14 & 11.9 & 104 & 88.1 & \\
\hline \multirow[t]{2}{*}{ Living nearby a source of pollution } & Yes & 16 & 15.5 & 87 & 84.5 & 0.29 \\
\hline & No & 54 & 20.4 & 211 & 79.6 & \\
\hline \multirow[t]{2}{*}{ Child live with } & Single parent & 15 & 71.4 & 6 & 28.6 & $0.001^{a}$ \\
\hline & Both parents & 55 & 15.9 & 292 & 84.1 & \\
\hline \multirow[t]{2}{*}{ Parent(s) death } & Yes & 12 & 63.2 & 7 & 36.8 & $0.001^{a}$ \\
\hline & No & 58 & 16.6 & 291 & 83.4 & \\
\hline \multirow[t]{2}{*}{ Parent(s) drug abuse } & Yes & 4 & 100.0 & 0 & 0.0 & $0.001^{a}$ \\
\hline & No & 66 & 18.6 & 288 & 81.4 & \\
\hline
\end{tabular}

${ }^{\mathrm{a}} \chi^{2}$ or exact test as appropriate

Other risk factors for CPD include living with a parent who is a drug abuser, stress, homelessness, poor housing, and social disadvantage [36, 38].

Our finding revealed that statistical significant relations between CPD among the studied children and their academic achievement, the interrelation between academic achievement and CPD has been proved by many researches as there is clear evidence that children who are emotionally or mentally healthy achieve more at school [39]. Also, children with mental problems can also adversely affect the social and academic environment for others in their school [40] However, a continuing debate on the relative impact of the home/work/school environment and peer groups on children mental health is still an important issue that needs further research activity [41]. The results of the present study revealed statistically significant relations between CPD among the studied children and problems with teachers, problems with peers, and exposure to violence. Similarly, other studies suggested several risk factors for childhood psychosocial problems including, childhood abuse, trauma, violence or neglect, social isolation, and loneliness or discrimination [38].
In the current study, there was no statistically significant relation between CPD among the studied children and living nearby a source of pollution and long use of television and computer $(P>0.05)$. However, a Swedish study found a link between exposure to air pollution and dispensed medications for certain psychiatric disorders in children and adolescents even at the relatively low levels of air pollution [42]. Furthermore, children in Spain who attended schools with higher traffic-related air pollution have been observed to have a smaller improvement in cognitive development than children who attended schools with lower traffic-related air pollution [43]. This discrepancy may be explained by lack of awareness of sources of pollution among surveyed parents.

\section{Strengths and limitations of the study}

One of the most important strengths of this study was assessing CPD among the studied sample of children using SDQ which is a standardized validated questionnaire which allows comparison of results among different countries and cultures. Also, in the present study, data was collected from the two informants (parents and 
teachers). However, one of the weaknesses of the study is that no independent confirmation of the diagnosis was made in children identified with probable disorders. Reliability and validity of the designed questionnaires were not tested. Also, Reliability of the teachers as a source of information in public schools due to large number of students in classes that may be one explanation of lower psychosocial comorbidities relative to other studies.

\section{Conclusion}

Childhood psychosocial dysfunction is a common problem among school children in Egypt with several identifiable risk factors. Hence, mental health services should be incorporated into primary health care facilities and school health program. It is crucial to train family physicians and primary health care providers about preventive measures needed.

\section{Abbreviations}

BMI: Body mass index; HPD: Childhood psychosocial dysfunction; PCH: Preventive Child Healthcare; PHC: Primary health care; SDQ: The extended strengths and difficulties questionnaire

\section{Acknowledgements}

Not applicable.

\section{Authors' contributions}

HF and RM designed the study and analyzed and interpreted the patient data. RS and ES analyzed and interpreted the patient data and contributed to writing the manuscript. RM collected the patients' data and applied the scales. All authors read and approved the final manuscript.

\section{Funding}

This research was funded by the Deanship of Scientific Research at Princess Nourah Bint Abdulrahman University through the Fast-track research Funding program.

\section{Availability of data and materials}

Available upon request.

\section{Ethics approval and consent to participate}

Approval was obtained from the Institutional Review Board (IRB), Ethics Committee of the Psychiatry Department, Zagazig University. The committee reference number is not applicable. Written informed consent was obtained from parents' participants after discussing with them the aim of the study.

\section{Consent for publication}

Not applicable.

\section{Competing interests}

The authors declare that they have no competing interests.

\author{
Author details \\ ${ }^{1}$ Clinical Science Department, College of Medicine, Princess Nourah Bint \\ Abdulrahman University, Riyadh, Kingdom of Saudi Arabia. ${ }^{2}$ Psychiatry \\ Department, Faculty of Medicine, Zagazig University, Zagazig, Egypt. \\ ${ }^{3}$ Community and Public health Department, Faculty of Medicine, Zagazig \\ University, Zagazig, Egypt.
}

Received: 19 February 2020 Accepted: 21 February 2020 Published online: 24 April 2020

\section{References}

1. Patel V, Araya R, Chatterjee S, Chisholm D, Cohen A, De Silva M, Hosman C, McGuire H, Rojas G, van Ommeren M (2007) Treatment and prevention of mental disorders in low-income and middle-income countries. Lancet 370(9591):991-1005
2. Theunissen MH, Vogels AG, Reijneveld SA (2012) Work experience and style explain variation among pediatricians in the detection of children with psychosocial problems. Acad Pediatr 12(6):495-501

3. Spijkers W, Jansen DE, Reijneveld SA (2013) Effectiveness of primary care triple $\mathrm{P}$ on child psychosocial problems in preventive child healthcare: a randomized controlled trial. BMC Med 11(1):240

4. Elhamid AA, Howe A, Reading R (2009) Prevalence of emotional and behavioural problems among 6-12 year old children in Egypt. Soc Psychiatry Psychiatr Epidemiol 44(1):8

5. Merikangas KR, He JP, Brody D, Fisher PW, Bourdon K, Koretz DS (2010) Prevalence and treatment of mental disorders among US children in the 2001-2004 NHANES. Pediatrics 125(1):75-81

6. Stadelmann S, Perren S, Groeben M, von Klitzing K (2010) Parental separation and children's behavioral/emotional problems: the impact of parental representations and family conflict. Fam Process 49(1):92-108

7. Erol N, Simsek Z, Münir K (2010) Mental health of adolescents reared in institutional care in Turkey: challenges and hope in the twenty-first century. Eur Child Adolesc Psychiatry 19(2):113-124

8. Kelleher KJ, McInerny TK, Gardner WP, Childs GE, Wasserman RC (2000) Increasing identification of psychosocial problems: 1979-1996. Pediatrics 105(6):1313-1321

9. Brugman E, Reijneveld SA, Verhulst FC, Verloove-Vanhorick SP (2001) Identification and management of psychosocial problems by preventive child health care. Arch Pediatr Adolesc Med 155(4):462-469

10. Vogels AG, Crone MR, Hoekstra F, Reijneveld SA (2009) Comparing three short questionnaires to detect psychosocial dysfunction among primary school children: a randomized method. BMC Public Health 9(1):489

11. Corrigan P (2004) How stigma interferes with mental health care. Am Psychol 59(7):614

12. Jaycox LH, Stein BD, Kataoka SH, Wong M, Fink A, Escudero P, Zaragoza C (2002) Violence exposure, posttraumatic stress disorder, and depressive symptoms among recent immigrant schoolchildren. J Am Acad Child Adolesc Psychiatry 41(9):1104-1110

13. Costello EJ, Egger $H$, Angold A (2005) 10-year research update review: the epidemiology of child and adolescent psychiatric disorders: I. methods and public health burden. J Am Acad Child Adolesc Psychiatry 44(10):972-986

14. Sirvinskiene G, Zemaitiene N, Zaborskis A, Markuniene E, Jusiene R (2012) Infant difficult behaviors in the context of perinatal biomedical conditions and early child environment. BMC Pediatr 12(1):44

15. Verhulst FC, Van Der Ende JA (1997) Factors associated with child mental health service use in the community. J Am Acad Child Adolesc Psychiatry 36(7):901-909

16. Durlak JA, Wells AM (1998) Evaluation of indicated preventive intervention (secondary prevention) mental health programs for children and adolescents. Am J Community Psychol 26(5):775-802

17. El-Gilany A, El-Wehady A, El-Wasify M (2012) Updating and validation of the socioeconomic status scale for health research in Egypt. East Mediterr Health J 18(9):962-968

18. [Internet]. Sdqinfo.com. 2017. Available from: http://www.sdqinfo.com/py/ sdqinfo/b3.py?language=Arabic. Cited 12 November 2017

19. Goodman R, Ford T, Corbin T, Meltzer H (2004) Using the Strengths and Difficulties Questionnaire (SDQ) multi-informant algorithm to screen lookedafter children for psychiatric disorders. Eur Child Adolesc Psychiatry 13:ii25-ii31

20. Youth in mind: scoring the SDQ strengths and difficulties quationnaire (available at http://www.sdqinfo.com.) accssed (2012):15-5-2015

21. [Internet]. Who.int. 2017. Available from: http://www.who.int/growthref/ who2007_bmi_for_age/en/. Cited 12 November 2017

22. Rutter M (2008) Epidemiological methods to tackle causal questions, pp 3-6

23. Lippman LH, Moore KA, Mclntosh H (2011) Positive indicators of child wellbeing: a conceptual framework, measures, and methodological issues. Appl Res Qual Life 6(4):425-449

24. Perou R, Bitsko RH, Blumberg SJ, Pastor P, Ghandour RM, Gfroerer JC, Hedden SL, Crosby AE, Visser SN, Schieve LA, Parks SE (2013) Mental health surveillance among children-United States, 2005-2011. MMWR Surveill Summ 62(Suppl 2):1-35

25. Egger HL, Angold A (2006) Common emotional and behavioral disorders in preschool children: presentation, nosology, and epidemiology. J Child Psychol Psychiatry 47(3-4):313-337

26. Mullick MS, Goodman R (2005) The prevalence of psychiatric disorders among 5-10 year olds in rural, urban and slum areas in Bangladesh. Soc Psychiatry Psychiatr Epidemiol 40(8):663-671 
27. Samad L, Hollis C, Prince M, Goodman R (2005) Child and adolescent psychopathology in a developing country: testing the validity of the strengths and difficulties questionnaire (Urdu version). Int J Methods Psychiatr Res 14(3):158-166

28. Meltzer H, Gatward R, Goodman R, Ford T (2003) Mental health of children and adolescents in Great Britain. Int Rev Psychiatry 15(1-2):185-187

29. Hudson CG (2005) Socioeconomic status and mental illness: tests of the social causation and selection hypotheses. Am J Orthop 75(1):3

30. Lund C, De Silva M, Plagerson S, Cooper S, Chisholm D, Das J, Knapp M, Patel V (2011) Poverty and mental disorders: breaking the cycle in lowincome and middle-income countries. Lancet 378(9801):1502-1514

31. Academy of Medical Sciences: An Academy of Medical Sciences working group report chaired by Sir Michael Rutter CBE FRS FBA FMed Sci: identifying the environmental causes of disease: how should we decide what to believe and when to take action? Academy of Medical Sciences (2007) (www.acmed.sci.ac.uk). Accessed Feb 2014

32. Swanson JD, Wadhwa PM (2008) Developmental origins of child mental health disorders. J Child Psychol Psychiatry 49(10):1009-1019

33. Thapar A, Rutter M (2009) Do prenatal risk factors cause psychiatric disorder? Be wary of causal claims, pp 100-101

34. Kieling C, Baker-Henningham H, Belfer M, Conti G, Ertem I, Omigbodun O, Rohde LA, Srinath S, Ulkuer N, Rahman A (2011) Child and adolescent mental health worldwide: evidence for action. Lancet 378(9801):1515-1525

35. Warschburger P, Fromme C, Petermann F, Wojtalla N, Oepen J (2001) Conceptualisation and evaluation of a cognitive-behavioural training programme for children and adolescents with obesity. Int J Obes Relat Disord 25(S1):93-95 Hampshire

36. World Health Organisation (2012): Caring for children and adolescent with mental disorders: setting WHO directions; ISBN 924159063 7. (http://www. who.int/mental_health/media/en/785).pdf (6 Sept 2014)

37. Goldber g Joseph: WebMD Mental Health Center View Article Sources Causes of Mental Illness Sources, MD on February 08, 2014. @2005-2015 Web ND.LIC

38. Hancock KJ, Mitrou F, Shipley M, Lawrence D, Zubrick SR (2013) A three generation study of the mental health relationships between grandparents, parents and children. BMC Psychiatry 13(1):299

39. Department of Health and Department for Children, Schools and Families. Guidance for schools on developing emotional health and wellbeing. (2007). At www.healthyschools.gov.uk/resources

40. NASUWT: The National Association of Schoolmasters Union of Women Teachers Identification and Management of Pupils with Mental HealtDifficulties (2006): A Study of UK Teachers'Experience(www.nasuwt.org. uk/Templates/Internal.asp?NodelD=71899)

41. Heinrich LM, Gullone E (2006) The clinical significance of loneliness: a literature review. Clin Psychol Rev 26(6):695-718

42. Oudin A, Bråbäck L, Åström DO, Strömgren M, Forsberg B (2016) Association between neighbourhood air pollution concentrations and dispensed medication for psychiatric disorders in a large longitudinal cohort of Swedish children and adolescents. BMJ Open 6(6):e010004

43. Sunyer J, Esnaola M, Alvarez-Pedrerol M (2015) Association between trafficrelated air pollution in schools and cognitive development in primary school children: a prospective cohort study. PLoS Med 12:e1001792

\section{Publisher's Note}

Springer Nature remains neutral with regard to jurisdictional claims in published maps and institutional affiliations.

\section{Submit your manuscript to a SpringerOpen ${ }^{\circ}$ journal and benefit from:}

- Convenient online submission

- Rigorous peer review

- Open access: articles freely available online

- High visibility within the field

- Retaining the copyright to your article

Submit your next manuscript at $\boldsymbol{\nabla}$ springeropen.com 